\title{
Konduktiv pedagogik - mellan evidens och existens?
}

\author{
ULLA BOHLIN
}

\begin{abstract}
Artikeln problematiserar evidenstänkandet i behandlingsmetoden konduktiv pedagogik. Dels uppmärksammas de metodologiska begränsningar som finns $i$ många studier av metoden, dels diskuteras att ensidigt fokus på mätbart utfall förbiser väsentliga frågor av mer existentiell natur som ligger utanför evidenssfären men som bör beaktas när arbetssättet värderas.
\end{abstract}

\section{Bakgrund och syfte}

I Sverige blev konduktiv pedagogik eller Petö-metoden (CE) på 1990-talet bekant via media genom den s.k. Mullbackdebatten. Lars Mullback, själv CP-skadad, visade hur CE på kort tid gjort honom kapabel till aktiviteter som professionell habilitering ansett omöjliga. ${ }^{1}$ Svensk habiliteringsorganisation angreps, Mullback hävdade att sjukvården underlåtit att introducera metoden och motarbetat den genom att döma ut den som kvacksalveri (Mullback 1997).

CP-skadade barn erbjuds behandling av barn- och ungdomshabiliteringens spe-

Ulla Bohlin, socionom och doktorand, Socialhögskolan, Lunds universitet. cialistteam (BUH) som därmed får starkt tolkningsföreträde för att bedöma lämpliga och olämpliga behandlingsmetoder. Huvudsakligen har BUH arbetat utifrån sjukgymnastik baserad på Bobathmetoden, alltjämt mest använd inom landstingsbaserad sjukvård (RBU 2000, SBU 2001). Andra arbetssätt har i olika epoker introducerats. De har oftast benämnts som "alternativa metoder" och därmed framstått som avvikelser från gängse behandlingsnorm. Det etablerade behandlingssystemet har ofta uttryckt skepsis mot alternativen och debatt har uppstått mellan företrädare och skeptiker. Debatten för eller emot konduktiv pedagogik är ett aktuellt exempel.

$1 \mathrm{CE}=$ Conductive education 
Evidenstänkandet är centralt för bedömningen av $\mathrm{CE}$, och artikelns syfte är att problematisera evidenstänkandet på två nivåer. ${ }^{2}$ Dels skärskådar jag de metodologiska begränsningar som finns i många publicerade studier av behandlingsförsöken med $\mathrm{CE}$, dels diskuterar jag mera kortfattat att en metodisk-teknisk kritisk läsning av »evidensen « vid en behandlingsmetod missar något väsentligt, dimensioner som inte låter sig mätas så enkelt och som berör frågor av mer existentiell natur och som ligger utanför evidenssfären. Därav artikelns titel: "Konduktiv pedagogik - mellan evidens och existens? « ${ }^{3}$

\section{CP-skadan, behandlings- metoderna och forskningen}

Cerebral pares, $(\mathrm{CP})$ är den vanligaste orsaken till rörelsehinder hos barn. I Sverige föds årligen ca 100000 barn varav 200 får en CPskada. CP är ingen enhetlig sjukdom utan ett samlingsnamn för många symtom där en skada eller utvecklingsrubbning i den ännu omogna hjärnan är gemensam nämnare. Sinsemellan skilda tillstånd beträffande etiologi, konsekvenser och prognos ryms under paraplybegreppet CP-skada.

2 "Evidence-based social care is the conscientious, explicit and judicious use of current best evidence in making decisions regarding the welfare of service-users and carers" (Sheldon \& Macdonald 1999).

3 Artikeln skrivs inom ramen för forskningsprojektet Habiliteringen ifrågasatt. Den konduktiva pedagogiken som organisatorisk, professionell och kunskapsteoretisk utmaning, finansierat av FAS (Dnr 2001-2106).
Behandlingen vid CP består av symtomlindring genom terapeutiska interventioner med ett brett insatsspektrum. Vanligast är medicinering, kirurgiska ingrepp, ortopediska hjälpmedel samt sjukgymnastik. Huvudprinciperna är behandling för att direkt påverka kroppsdelen som inte fungerar, neurofysiologisk behandling som påverkar centrala nervsystemet samt pedagogisk träning för att uppmuntra barnet till ändamålsenligare rörelsemönster (Scrutton 2004).

Förutom sjukgymnastik grundad i Bobathmetoden arbetar sjukgymnaster eklektiskt och kombinerar metoder baserade på neurofysiologi och inlärningsteorier (Brogren 1999, Ulfhielm 2001).

BUH:s arbetsmetoder har efterhand förfinats och effektiviserats mot interdisciplinära, familjecentrerade och strukturerade modeller. I tiden ligger att utveckla behandlingsstrategier med dokumenterad effekt mätt utifrån vedertagna kriterier för evidensbaserat kliniskt arbete. ${ }^{4}$ Behandling ska bygga på vetenskap och beprövad erfarenhet, föräldrar och allmänhet har rätt att veta att behandlingen har avsedd verkan och sjukvården får inte bedriva kvacksalve-

4 Sackett (1989) bedömer evidens på fem nivåer utifrån forskningsdesign: I: randomiserat kontrollerat urval (RCT), II: icke-randomiserat kontrollerat urval och prospektiva kohortstudier med motsvarande kontrollgrupp, III: fallkontrollstudier, IV: före-efter-studier utan kontrollgrupp, V: beskrivande fallstudier, berättelser, åsikter från expertis. På nivå I är det möjligt att uttala sig med avsevärd säkerhet om utfallet, på nivå II måste resultaten betraktas som troliga, på nivå III och IV kan samband endast vara möjliga, på nivå $\mathrm{V}$ kan inga samband styrkas. 
riverksamhet. ${ }^{5}$ Denna ambition har uppenbarligen varit svår att leva upp till för såväl det etablerade habiliteringssystemet som de "alternativa metoderna" (Brogren 1999, SBU 2001, Scrutton 2004). Siebes et al. (2002) konstaterar att det är svårt att slå fast evidens i studier inom funktionshinderområdet. Experterna verkar överens om att få behandlingsmetoder för $\mathrm{CP}$ är vetenskapligt genomlysta och evidensprövade. Praxis baserar sig ofta på "common sense" och kliniska observationer. Frågan "Vad är den bästa behandlingen för ett CP-skadat barn?" besvaras inte enkelt. Skadorna är komplexa och standardiserade diagnostekniker och interventioner saknas (Scrutton 2004). Randomiserade studier försvåras eftersom möjliga populationer är små. Ofta framhålls att varje barn har en närmast unik skadebild och selektion och matchning är problematisk. ${ }^{6}$

\section{Konduktiv pedagogik, $\mathrm{CE}$}

CE benämns ofta som en walternativ metod" och erbjuds inte mer än undantagsvis som en valmöjlighet inom BUH. Situationen är likartad utomlands där centra

5 Statens beredning för medicinsk utvärdering (SBU) graderar studiers bevisvärde på tre nivåer: högt, medelhögt och lågt. Evidensstyrkan anges som 1- starkt vetenskapligt underlag, 2- måttligt starkt vetenskapligt underlag, 3-begränsat vetenskapligt underlag. (www.sbu.se)

6 Se exempelvis CPUP-studien, kontinuerlig uppföljning av samtliga 167 CP-skadade barn födda 1990-1993 i Sydsverige (Nordmark et al. 2001). Inom gruppen finns stor spridning beträffande CP-diagnoser och tilläggshandikapp. för CE skapas vid sidan av det allmänna hälsosystemet. CE utgör i denna mening en konkurrerande diskurs som utmanar det etablerade behandlingssystemet. Spänningar mellan föreställningar om problem och interventioner uppstår och i vissa fall kan dessa beskrivas som diskursiva strider (Brante 1984).

CE är en holistisk inlärningsfilosofi som förutsätter att barn med motoriska problem kan ändra sina dysfunktioner mot ett mer ändamålsenligt bemästrande inom alla inlärningsområden. Stor vikt läggs vid intensiv träning och daglig stimulans. Metoden utvecklades i Ungern i slutet av 1940-talet av András Petö och i Budapest bedrivs en fyraårig grundutbildning av "conductors", yrkesgruppen som leder det pedagogiska arbetet. En snabb orientering om det typiska med CE brukar framhålla följande:

1. Conductorn är lärare och terapeut i kombination

2. Målinriktad träning med "task series"

3. "Rytmisk intention" = Barnet säger/ sjunger rörelserna

4. Intensivträning i grupp

5. Specialutrustad träningsmiljö

6. Tekniska hjälpmedel minimeras

7. Behandlingsfilosofin betraktar motoriska handikapp som pedagogiska problem

8. Målsättningen:uppnå orthofunktion, dvs. barnets mest effektiva rörelsemönster oavsett "normalt" mönster. Självkänsla och attityd betonas.

(Brown 1999, Hari \& Akos 1988, Lonton \& Russell 1989, Macdonald 2001)

Internationellt har $\mathrm{CE}$ debatterats sedan 
introduktionen i västvärlden i början av 1970-talet. Via media presenterades metoden i Sverige 1996 och väckte uppmärksamhet. Denna "outsider« skilde sig i vissa avseenden från förhärskande föreställningar om hur CP-skadan bör behandlas (Liljeroth 2004, Lind 2003, Mullback 1997). Det etablerade medicinska systemet fick konkurrens och parterna stred för makten över kunskapen om behandlingsmetoderna. I CE-debatten har enskilda forskare och andra positionerat sig. Förespråkare anser att metoden har legitimitet antingen utifrån subjektiva observationer av praxis eller studier genomförda med vetenskaplig design (Llewellyn et al. 1997, Macdonald 2001, Sutton 1984, Trevarthen \& Burford 1995). Kritiker menar att CE-systemet saknar teoretisk bas och att behandlingen inte visat sig verkningsfull jämfört med gängse metoder (Bairstow et al. 1991, Eliasson 2000, Reddihough et al. 1998). Tueksamma konstaterar att studierna ofta saknar tillförlitlig utvärderingsteknik varför frågan om metodens relevans måste lämnas öppen. Entydiga bedömningskriterier efterlyses. Bedömningarna anses i flera fall ha gjorts av subjektiva intressenter t.ex. conductors och värdet av resultaten har ifrågasatts (Lind 2000, Stukat 1995). Ett fåtal studier har dock genomförts i syfte att utvärdera metoden enligt vetenskapliga kriterier. ${ }^{7} \mathrm{CE}$ förefaller varken bättre eller sämre än andra metoder men eftersom den inte har konstaterats medföra skada så bör CE kunna erbjudas som ett alternativ menar många.

7 Se fotnot 4 och 5 .

\section{Kunskapsläget för CE}

Följande redovisning av kunskapsläget bygger på en genomgång av litteratur, vetenskapliga rapporter och artiklar som behandlar CE-behandling av barn med CPskador. ${ }^{8}$ Med utgångspunkt från forskningsartiklarna inklusive de fyra forskningsöversikterna, nyhets- och debattartiklarna analyserar jag nedan hur kunskapen om CE görs och framställs i materialet. ${ }^{9}$ Hur har studierna genomförts, vad har de syftat till, vilka resultat kommer man fram till och vilka reflektioner görs utifrån resultaten? Vilka mönster skönjs i kunskapsbilden?

\section{Motsägelsefulla tolkningar av utfallet}

I de granskade forskningsöversikterna har forskarna försökt tillämpa strikta inklusionskriterier för att öka vetenskapligheten. Trots detta kan de inte uttala sig säkert om metodens eventuella effektivitet jämfört

8 Litteratursökning på sökord Conductive education i databaserna Eric, Medline och Cinahl gav 139 artiklar publicerade 1984-2006. 19 behandlade utvärderingsstudier av CE-behandling inklusive fyra forskningsöversikter. Sökning i Artikelsök gav 14 nyhets- och debattartiklar, sökord konduktiv pedagogik och Move \&Walk. Medvetet valdes breda inklusionskriterier då mångfald eftersträvades i analysen. CEbehandling för andra tillstånd än CP-skador har dock exkluderats. Avstämning mot Google Scholar i april 2007, sökord Conductive education ger 510 träffar varav 16 här använda källor är citerade minst två gånger.

9 Se Tabell I för översikt över de studier som ingår i de fyra forskningsöversikterna. 
med andra konventionella träningsprogram. Av Vorland Pedersens (2000) nio granskade studier visar endast tre resultat som talar till fördel för $\mathrm{CE}$ på någon av de testade variablerna. Darrah et al. (2004) konkluderar att studierna sammantaget varken stödjer eller förkastar CE som behandlingsmetod. Det finns ingen stark evidens för dess effektivitet.

En uppmärksammad studie är den s.k. Birminghamstudien som på uppdrag av brittiska regeringen utvärderade verksamheten vid The National Institute of Conductive Education i Birmingham (Bairstow et al. 1993). Studien visade att projektbarnen gjorde framsteg mätt med många olika utvecklingsmått, men om någon slutsats kunde dras var det snarast att kontrollgruppsbarnen gjorde större framsteg. Rapporten väckte starka reaktioner inom CE-kretsar och ifrågasattes då man menade att barnen inte kommit till sin rätt i försökssituationen. Kritiken bemöttes av företrädare för konventionell behandling som tvärtom ansåg att alternativ till traditionell behandling alltid tenderar att framställas i positiv dager (Vorland Pedersen 2000). Stukat (1995) har granskat Birminghamstudien samt ett forskningsprojekt (Weber \& Rochel 1992) som syftade till att utveckla en tysk anpassning av det ungerska CE-programmet. Båda studierna berör små, heterogena populationer. Det tyska programmet var en pilotstudie som utvärderades av de involverade medan det brittiska externutvärderades. Stukat pekar på svårigheterna att dra säkra slutsatser eftersom det tyska programmet i praktiken saknade kontrollgrupp (se fotnot 4) medan det brittiska visserligen hade en kontrollgrupp men denna var inte randomiserad.

I debatten efter Birminghamrapportens publicering citerades ofta konklusionen:

"1... until it can be demonstrated that conductive education meets the expectation of its protagonists, the following conclusions are appropriate: staff involved with United Kingdom special education should be circumspect in their view of conductive education and should not feel compelled to adopt the met hods which are advocated; parents of children with cerebral palsy should regard with caution the promises made on behalf of conductive education and they should not feel they are failing, if they do not secure conductive education for their child" (Bairstow et al. 1993 s. 52).

Stukat (1995) noterar att resultaten i Birminghamstudien och det tyska projektet inte skiljer sig nämnvärt. I båda projekten rapporteras att både experiment- och kontrollgruppen har gjort framsteg. Resultaten är dock svårtolkade och motsägelsefulla. Den brittiska forskargruppens slutsatser uttrycks i reserverade eller direkt negativa ordalag medan den tyska forskargruppen beskriver resultaten som lovande!

Frågan "Är CE en bra behandlingsmetod eller inte för CP-skadade personer?" kan inte besvaras entydigt. Det blir därför problematiskt när Darrah et al. (2004) rekommenderar föräldrar att ta del av deras evidensrapport för att fatta beslut om träningsalternativ. Sak samma gäller Birminghamstudien. Nyare forskning visar dessutom att även experter är osäkra och okunniga om CE-metoden, vilket är bekymmer- 
samt när behandlingsalternativ ska övervägas och förhandlas (Lind 2002, Morgan \& Hogan 2005, Taylor \& Emery 1995).

Forskningsrapporterna lämnar öppet för vida och motsägelsefulla tolkningar. Problemen med tolkningarna kan som nämnts hänföras till två nivåer: dels forskningsmetodologiska svårigheter, dels svårigheter utifrån oklara målsättningar med behandlingen.

\section{Forskningsmetodologiska svagheter}

\section{Urvalspopulationen}

\subsection{Diagnosgränsdragning: CP-skador kan} te sig mycket olika och det är svårt att skapa homogena barngrupper att studera. Vissa barn i studierna har inte CP-skador utan andra motoriska funktionshinder. Många har också andra funktionshinder som kognitiva och sensoriska handikapp vilket komplicerar bilden ytterligare (Bairstow et al. 1991). En ofta framförd uppfattning är att CE utanför Ungern inkluderar barn som inte skulle komma ifråga för träning $\mathrm{i}$ sin ungerska ursprungskontext, som barn med utvecklingsstörning, epilepsi, sensoriska handikapp och muskelsjukdomar. Ett exempel är studien där experimentgruppen bestod av gravt utvecklingsstörda, multihandikappade barn (Cottam et al. 1985). Det framhålls i många sammanhang att barn med dessa diagnoser inte anses kunna tillgodogöra sig CE-behandling särskilt bra. I French \& Nommensen (1992) sex analyserade studier hade barnen hete- rogena diagnoser, likaså i de två studier som Stukat (1995) granskat.

1.2 Ålder: Vissa hävdar att tidiga behandlings- och träningsinsatser är betydelsefulla, kanske livsavgörande (Scrutton 2004). Andra pekar på att barn som fått sjukgymnastik tidigt i livet inte skiljde sig från kontrollgruppen som fått allsidig lekstimulans (Forssberg et al. 1998). Ålder är endast ganska grovt beaktad i de flesta studierna och spridningen åldersmässigt kan vara avsevärd i en träningsgrupp.

\section{3 Övriga bakgrundsfaktorer som kön,} etnisk bakgrund och socioekonomiska förhållanden brukar tillmätas betydelse i pedagogiskt och terapeutiskt förändringsarbete. Hurwitz et al. (2003) undersökte familjers användning av komplementäroch alternativmedicin för barn med CPskador och fann samband med föräldrars utbildning, ålder och egna erfarenheter av behandlingsmetoderna. Föreställningar om behandling och bot konstrueras i en social och kulturell kontext (Bohlin 2001, Reynolds Whyte \& Ingstad 1995, Richt \& Tegern 2005). Ingen CE-studie har dock beaktat dessa variabler. I debatten förekommer ibland uppfattningen att föräldrar till barn som får träning i CE-program är speciella i meningen aktiva och bra på att kräva insatser jämfört med familjer som inte valt $\mathrm{CE}$-träning. Detta är dock inte systematiskt undersökt. Studien Hysteriska mammor eller mammor som inte vill missa tåget. Move \& Walk utifrån ett föräldraperspektiv (Wallin 2000) fokuserar föräldrars (läs: mammors) upplevelser av CEträning och författaren tolkar mammornas 
förhållningssätt utifrån deras speciella "handikappföräldraskap" (ibid. s. 60). ${ }^{10} \AA$ ena sidan tycks Move \& Walk-deltagandet engagera »starka föräldrar med stora krav på sig själva«, å andra sidan menar Wallin att mödrarna "på intet sätt är några ovanliga mammor« (ibid. s. 60).

Är då barnen på något sätt »speciella»? Sker det en selektion till metoden utifrån barnens speciella förutsättningar eller deras inställning till träningen? I studierna anges endast diagnoser medan faktorer som temperament eller copingstrategier inte beaktas. En annan möjlighet är att barnet förändras genom träningen. Föräldrar till barn som fått Move \& Walk-träning beskrev att i gruppträningen blev barnet ett av många, att ha CP kändes normalt och barnets självkänsla ökade (Lind 2000).

\subsection{Samma studier kan återkomma i olika} översikter och därmed få orimligt stor betydelse. De undersökta barnens framgångar eller tillkortakommanden präglar helhetsbilden vilket kan vara missvisande. Det gäller exempelvis Coleman \& King (1990) och Coleman et al. (1995) som tas upp i French \& Nommensen (1992) samt Bairstow et al. (1993), Hur \& Cochrane (1995a) samt Hur (1997) inkluderade i Vorland Pedersen (2000). Om man i en sammanställning av forskningsöversikterna tycker sig se mönster bör man beakta att slutsatserna baserar sig på ett begränsat antal observationer av i vissa fall samma barn.

10 Det första träningsinstitut för CE som startade i Sverige 1997.

\section{Programmets karakteristika}

2.1 I klinisk forskning tillmäts experimentsituationen i regel stor betydelse, men i sammanställningarna kan sällan detaljer i studiernas uppläggning och innehaill utläsas. Informationen om experimentbarnens träning är knapphändig och det går inte att konkludera vilka element som eventuellt haft effekt. CE betonar struktur och standardisering av den fysiska miljön och vissa kriterier ska som nämnts föreligga. Beskrivningar, intryck och upplevelser kan dock vara påfallande olika i praktiken, både av olika verksamheter med samma "etikett" men även när olika observatörer beskriver samma träningssituationer. Så här olika beskrivs t.ex. träningsmiljöerna på Move \& Walk och Petö-institutet: "För öurigt var miliön lugn och trevlig och gruppen var lagom stor ( 3 barn) så att alla kunde få 'komma till tals' " (Björk \& Hasselgren 1994 s. 68). "Vårt samlade intryck var en känsla av beklämning" (Lundgren 1997 s. 15).

Under de fyra decennier som CE funnits har metoden naturligtvis modifierats (Hari \& Tillemans 1984). Trots en grundläggande skepsis mot hjälpmedel och anpassningar förekommer sådana. Eftersom inställningen till personliga hjälpmedel är kontroversiell, se t.ex. Mullbackdebatten, är det angeläget att förutsättningarna i det enskilda fallet redovisas.

2.2 Interventionerna för både experimentoch kontrollgrupp är svåra att renodla men fokus ligger på att granska experimentet. Sällan preciseras kontrollgruppbarnens träning. Allt kallas "konventionell träning", 
"traditionell undervisning", "specialundervisning", »intensivträning" eller »eklektisk metod" (Cooper 1986, Chu 1989). Vad jämförs egentligen? Resonemanget förs som om all annan träning än CE vore entydig och baserad på tydliga principer. Undantag är en svensk studie om intensivträning med Move \& Walk respektive Lemo-metoden (Ödman \& Öberg 2005).

\subsection{Vem leder och genomför programmet?} Conductorn framhålls i själva verket som den största skillnaden mellan CE och andra arbetssätt (Bairstow et al. 1993). Konsekvensen av att en person är vallt-i-allo« med kunskap inom skilda discipliner som specialpedagogik, logopedi, arbetsterapi, psykologi och sjukgymnastik diskuteras (Bochner \& Center 1996). Oavsett ståndpunkt bör träningsansvaret redovisas i projekten. Conductorns uppgifter framgår inte alltid. I French \& Nommensens (1992) metastudie varierade conductorns roll. Andra yrkesföreträdare har också uppgetts som ansvariga (Brown et al. 1998).

\subsection{Behandlingsintensiteten och varaktig-} heten anges sällan trots att studier visat att intensiv, målinriktad sjukgymnastisk behandling integrerad i dagliga livet kan ge varaktiga motoriska effekter (t.ex. Bower et al. 1996). Hur mycket tid får träningsbarnen och kontrollgruppen? Att jämföra daglig träning med några få timmars träning per vecka är som att jämföra toppatleten med amatören menar Vorland Pedersen (2000 s. 79).

2.5 Föräldrars, assistenters och andra personers engagemang är ofta oklart. Famil- jen brukar betonas som framgångsfaktor i behandling (Jansen et al. 2003, Scrutton 2004). I CE-program framhålls just föräldrars aktiva roll i träningssituationen. Genom deltagandet ökas föräldrakompetensen för hur barnet kan stödjas i sin utveckling. Mötet med andra föräldrar upplevs som stärkande och meningsfullt (Lind 1996).

2.6 Ges programmet i internatform eller $i$ barnets vardagsmiljö? Att resa bort och intensivträna beskrivs av många som ansträngande och problematiskt men kan också vara motivationshöjande. Familjer som söker alternativa behandlingsmetoder önskar något utöver traditionell behandling. De gör ett aktivt val, avsevärda ansträngningar och ekonomiska uppoffringar vilket i sig kan stärka övertygelsen om positiva resultat. Robinson et al. (1989) talar om "pilgrimsfärdseffekten». Barn, behandlare och föräldrar är välmotiverade i träningssituationen vilket spelar roll för utfallet. Föräldrar i Linds studie (2000) uppskattade att kunna ägna sig åt barnet helhjärtat utan att behöva engagera sig i vardagsplikterna.

\section{Studiens vetenskapliga design}

\begin{abstract}
3.1 Många studiers urvalsprincip kan kritiseras. Klassificerade med Sacketts bedömningssystem för evidens är endast två av 19 studier i de översikterna på nivå I (RCTstudier). ${ }^{11}$ Flest studier ligger på evidensnivåerna III-V, vilket reser frågetecken kring generaliserbarhet och validitet.
\end{abstract}

11 Se fotnot 4 
Forskarna (t.ex. Reddihough et al. 1998, Weber \& Rochel 1992) är tveksamma till randomisering av etiska skäl. Motståndet i det tyska projektet mot kontrollgruppsdesign motiverades både etiskt och metodologiskt (Stukat 1995). Forskningsetiska överväganden kan alltså påverka strävan att nå god evidens negativt.

\subsection{Antal (n). Vissa studier har så få delta-} gare att det blir problematiskt att behandla data statistiskt. ${ }^{12}$ Weber \& Rochel (1992) har 12 barn i experimentgruppen och Bairstow et al. (1993) har 19. Heal (1974) inkluderar 10 barn och Calderon-Gonzalez et al. (1989) gäller 22 barn totalt. Extremt blir det i metastudien Darrah et al. (2004) som inkluderar Cotton (1974) 2(n), Titchener (1983) med 8(n), Sigafoos et al. (1993) 4(n) respektive 5(n).

\subsection{Hur lång tid pågår studien och när} mäter man utfallet? Studierna varierar i tidsutdräkt från några veckor till flera år. Som andra forskare påpekat finns det reella problem vad gäller när och hur interventioners effekter gör sig gällande och hur beständiga de är (Soydan \& Vinnerljung 2002s. 167).

\subsection{Vem genomför och utvärderar? Även} omsorgsfulla studier med nivå I-design kan inrymma svagheter i genomförandet. Både internvaliditet och reliabilitet kan vara svaga länkar (se t.ex. Pawson \& Tilley

12 French \& Nommensen (1992) stöder sig på Pagano som menar att antal (n) ska överstiga 30 för att parametrisk statistisk teknik kan användas (ibid. s. 22).
2005). Om olika slutsatser dras utifrån resultat som är lika kanske detta hänger samman med forskarnas roll. Har utfallet bedömts av aktivt deltagande conductors, sjukgymnaster eller oberoende forskare? I Birminghamstudien fann man att conductorerna noterade fler framsteg än forskargruppen (Bairstow et al. 1993).

En parallell kan dras till psykoterapiforskningen som talar om allegiance, dvs. forskarens egen inställning till metoden har betydelse för utfallet (Larsson 2006). Han/hon tvingas ofta till val och beslutsfattande i behandlingssituationen som i förlängningen kan påverka utfallet av den undersökta terapiformen. För att minska allegiance-effekten bör forskare med olika terapeutisk inriktning engageras, alternativt personer vars allegiance är riktad mot annan behandling eller är neutral skriver Larsson (ibid. s. 19). Flera av CE-studierna är genomförda av samma forskargrupp, vilket reser frågor om betydelsen av forskarens perspektiv och förförståelse.

\subsection{Tidsmässig, social och kulturell kon-} text bör beaktas när arbetssätt analyseras och resultat värderas. Metoder utformade och verkningsfulla i ett sammanhang är inte nödvändigtvis genomgående relevanta. Synen på barn, motorisk träning och pedagogik förändras naturligtvis över tid. Diskussionen om "metodtransplantation", huruvida man kan transplantera ett klassiskt CE-program till en annan social och kulturell kontext aktualiseras. Vad måste modifieras och anpassas till det aktuella sammanhanget och hur långt kan man fjärma sig från originalmodellen utan att förlora själva grundprinciperna (Darrah et 
al. 2004, Bairstow \& Cochrane 1993)? När forskningsöversikterna publicerades var vissa ingående studier redan påfallande gamla, vilket borde ha betydelse för tolkningarna. French \& Nommensens (1992) första studie publicerades 1973, Vorland Pedersens (2000) äldsta hade då 26 år på nacken och Darrah et al. (2004) inkluderar tre studier äldre än 30 år.

\section{Bearbetningav statistiska data}

4.1 Trots standardiserade processer kanske enskilda data inte alltid bearbetas och kodas entydigt. I fallet CE är mängden observationer begränsad och även om statistiska metoder finns för bearbetning av mindre material är det tveksamt om så är lämpligt. Se f.ö. pkt 3.2.

\section{Utfallsmått}

Slutligen utfallsmåtten: vad mäter man? Sedan den första studien (Heal 1972a) gjordes har flera standardiserade och validerade måttsystem utvecklats (Beckung et al. 2002 s. 126-141). När resultat från olika studier jämförs, hur vet vi då att de använda testerna är kompatibla? Kan vi någonsin skapa mått finkalibriga nog att ringa in subtila nyanser (validitetsproblemet)? Vissa förändringar är knappt urskiljbara för ögat men kan vara betydelsefulla för det enskilda barnet. Vissa mål är grovt tillyxade och kan ifrågasättas på dessa grunder, t.ex. 'orthofunktion' som är svårt att operationalisera. Utfallsstudierna fokuserar framförallt bar- nets motoriska färdigheter, i vissa fall kognitiva funktioner. Pragmatiskt mäts fenomen som låter sig mätas. En studie av ett skolbaserat CE-träningsprogram visade att valida och känsliga måttsystem för psykosociala dimensioner behöver utvecklas (Wright et al. 2005 s. 291). Aspekter som lek, språk, personliga/sociala förhållanden och familjesamspel framhålls i CE-metoden och bör beaktas när effekterna bedöms.

\section{Evidens och existens}

Forskningsgenomgången genererar således skilda reflektioner. För det första förutsättningarna för själva forskningsprocessen: vilka felkällor finns i materialet och hur kan dessa påverka kunskapsproduktionen? Frågan är som sagt kopplad till resonemanget om evidens i en vetenskapsmetodologisk betydelse. Även om vi lyckas konstruera finkalibriga mätinstrument som fångar motoriska förändringar tycks det problematiskt att renodla "laboratorielika" träningssituationer som erbjuder evidensmässiga förhållanden. Skulle detta konststycke lyckas så kvarstår nästa fråga: vilken typ av effekter är vi intresserade av att upptäcka och förhålla oss till? Möjligen finns det andra mål som är betydelsefulla och meningsfulla men som faller utanför den evidensinriktade sfären? Enkelt uttryckt är CEföreträdare och habiliteringsföreträdare oftast överens om det övergripande målet med insatserna: barnet ska kunna fungera optimalt med sin CP-skada. Robinson et al. (1989) talar om "functioning adequately in society without aids" (ibid. s. 1145). 
Inom habiliteringen betonas däremot barnets rätt till hjälpmedel. Vilken tolkning av "optimalt» ska vara tongivande, och hur mäter man detta? Frågan "vad fungerar? « i vård och behandling får kanske olika svar beroende på intressenten (Pawson \& Tilley 2005) och jag menar att här föreligger ett spänningsfält mellan en evidensproblematik och en existensproblematik i betydelsen vad är wrätt» för just detta CP-skadade barn?

En grundläggande fråga är ifall utfallsmåtten verkligen kan fånga programmens filosofi och »själ»? CE-förespråkare betonar att metoden bygger på föreställningar om CP-skadan och behandlingen som skiljer sig från traditionell sjukgymnastik. CE är pedagogik snarare än medicinsk behandling och metoden sägs vila på en holistisk filosofi (Coles \& Zsargo 1998). Utan att i detta sammanhang gå in på i vilket avseende dessa föreställningar skiljer sig eller sammanfaller med andra metoder vill jag ändå peka på att man knappast kan förbigå de diskursiva föreställningarna om CE om man vill göra en rättvis betraktelse av metoden.

\section{Svårmätbara aspekter}

Andra behandlingseffekter än motoriska förbättringar hos barnet kan också uppmärksammas, de kan vara betydelsefulla men dessvärre ofta svåra att mäta. Hur värderas t.ex. behandlingsalternativen i termer av upplevt välbefinnande och känsla av sammanhang hos barnet och familjen? Vem har makt och kontroll över behandlingen och hur sker samspelet mellan olika inblandade subjekt? Makten över beslut om behandling och träning har traditionellt legat hos expertisen. Strävan att evidensbasera insatser kan ställas emot idealet om den enskilda individens eget val och frågan reses då om vem som har tolkningsföreträde, den professionella experten eller patienten som expert på sina egna behov? I den aktuella diskursen om rehabilitering och habilitering framhålls vikten av samspel med patienten, för BUH är samarbetet med föräldrar en normativt självklar utgångspunkt (Beckung et al. 2002, Sanner 1999, Möller \& Nyman 2003). Var går då gränsen för föräldrars rätt att välja i förhållande till de professionella? Hur förhandlas gränserna och hur positionerar sig olika aktörer? Hur präglas mötet mellan praktiker och patienter av över/underordning, samarbete och kommunikation? Åkerström belyser hur föräldrar eftersöker expertkunskaper samtidigt som de önskar att deras egen kompetens erkänns (Åkerström 2004). Barn med CP-skador uppfattas som särskilt utsatta. Deras problem är varaktiga, de riskerar att hamna i beroende och vanmakt, deras fysiska och psykologiska integritet hotas och de företräds ofta av andra som vet bäst, som föräldrar och behandlingsexpertis. Studier visar att barns delaktighet riskerar att underordnas andra intressen (Bernehäll Claesson 2004, Bolin et al. 2003). Det finns en risk att, tillspetsat uttryckt, barnen i habiliteringen blir habiliteringens barn istället för att habiliteringen blir barnens. Bricher \& Darbyshire (2004) uppmärksammar att unga funktionshindrade inte självklart delar hälsoexperters och föräldrars uppfattning om lyckad behandling. Hur beaktas barnperspektivet när behandlingsalternativ prioriteras? Jag vill aktualisera frågan om individens rättigheter kontra 
samhällets skyldigheter att tillhandahålla dessa.

Mitt "case", motorisk träning av CP-skadade barn, innebär en mångdimensionell problematik med medicinska, sociala, psykologiska, pedagogiska med flera infallsvinklar. Sak samma gäller t.ex. missbruksvård, barn och ungdomspsykiatri, socialtjänstens vård av unga samt kriminalvård. Motsvarande kritiska analys kan appliceras på många exempel från praxisfältet för socialt arbete. Inom socialt arbete har evidensbaserade kunskapssystem och evidensbaserad praxis kommit att betraktas som en lösning på problemet med att bemästra stundtals oöversiktliga utmaningar (Angel 2003, Marthinsen 2004). Debatten förs om utvärderingsmodeller, evidensbaserad policy (EBP) och villkoren för kunskapsuppbyggnad inom det sociala arbetets forskning och praktik (Bergmark \& Lundström 2006, Månsson 2003, Pawson \& Tilley 2005, Webb 2001). Här framhålls att socialt arbete är komplext och svårfångat och att de metoder som används är interaktiva och bygger på intuition och inte enkelt låter sig fångas in i mätbara kategorier och tydliga utfallsmått. EBP grundar sig i föreställningen om rationella aktörer (socialarbetare och klienter) $i$ en rationellt fungerande organisation och bortser från att socialt arbete styrs av faktorer bortom rationalitet såsom politik, ideologi och organisatoriska särintressen.

\section{Vetenskapsbaserad behandling - det beror på}

I grunden förefaller alla vara överens om att behandling, oavsett inriktning, ska vara vetenskapsbaserad. Men hur definieras då vetenskapsbaserad? Evidensbegreppet genererar en debatt om vad som är vetenskap. Förståelse och tolkningsorienterade positioner riskerar att ställas emot nypositivism menar Marthinsen (2004). I den rådande diskursen uppfattas evidens ge legitimitet åt insatserna. Idealt sett ska patienten kunna ta ställning på grundval av god kunskap och korrekt information om behandlingsalternativ. Föräldrar och barn har rätt att få hjälp och behandling som håller måttet. Patientinflytande och den enskildes rätt att välja behandling betonas också. Genomgången av CE-studierna belyser metodologiska svagheter. De brister som vidlåder CE-forskningen grundar sig i samma realiteter som för forskning om habilitering (eller socialtjänst, kriminalvård och psykiatri). BUHs insatser kännetecknas också av att de är svårfångade när man försöker "mäta och väga» dem. Att konstruera vetenskapliga studier med god evidens är utmanande oavsett vilka behandlingsmetoder för CP-skadade man studerar.

Med de kriterier som befintlig forskning använder visar studierna att CE-metoden varken är bättre eller sämre än annan behandling av CP-skador. Bristen på tydliga utfall gör att resultaten kan tolkas som att "det beror påı. Därmed kan olika intressenter, både förespråkare för CE-metoden, skeptiker och belackare av den, stärka sina kunskapsanspråk vilket jag menar sker i debatten om CE som behandlingsmetod. Men om CE inte kan sägas vara skadlig och det råder delade meningar om dess verkan: borde den då inte betraktas som en av många habiliteringsmetoder? Och om inte: hur kan man förstå detta? Egelund (2006) 
reflekterar över ett orättvist dilemma i socialt arbete, nämligen att nya metoder blir föremål för extensiv diskussion och därmed sårbara medan etablerade delar av praxis inte underkastas samma kritiska granskning. Ett aktuellt exempel är metaanalysen om effekterna av multisystemisk terapi (MST) (Littell et al. 2005). Ogden och Hagen (2006) menar att orimligt höga standardiseringskrav på de ingående undersökningarna ställts, varför många studier exkluderats. Därmed faller kunskap som kunde givit viktiga bidrag för att värdera metoden bort. Ytterligare ett exempel är Gordon Halls meta-analys av behandling av sexualbrottslingar (Månsson 2003). Den kunskap som alltså tenderar att exkluderas har karaktären av praxiskunskap, Schön (2003) kallar den tyst kunskap och den förblir alltså tyst när hårddata ställs emot reflektion och djupstudier av komplexa fenomen.

Föreställningarna om förändring av mänskligt beteende genom sociala projekt grundar sig i en positivistisk förståelse av sociala samband menar Pawson \& Tilley (2005). De avvisar idén om experimentell utvärdering som alltid kommer att resultera i motsägelsefulla resultat och osäkra slutsatser om "what works". Dessutom framhålls "the black box problem", vad som egentligen sker i kontexten t.ex. innanför institutionernas väggar är omöjligt att kartlägga, beskriva och kontrollera. Frågan om vilka ingredienser som är verkningsfulla i projektet/experimentet besvaras inte (ibid. s. 30). Gör behandlingen skillnad, på vilket sätt och vad är det som åstadkommer skillnad?

\section{Avslutning}

Jakten på evidens i mitt »case»CE kan sluta på två sätt: kanske man lyckas åstadkomma en undersökningssituation där alla vetenskapliga hänsyn beaktas och i så fall kan man säkrare slå fast huruvida de behandlingsmetoder man mäter är effektiva, med reservationen att vissa faktorer inte går att fånga med tillgängliga utfallsmått. Kanske man istället bestämmer sig för att överge ambitionen att "mäta och väga» de effekter som befinner sig i vad jag väljer att kalla "den evidensfria zonen». Enligt många CE-förespråkare gör inte evidensbaserade metoder rättvisa åt den konduktiva pedagogikens »själ». Behandling är inte intressant enbart som en väg till förbättrade motoriska eller kognitiva prestationer utan bör ses i ett helhetsperspektiv: man får ett bättre sätt att hantera hela livet. Det handlar till sist om existentiella frågor. Självklart kan man tänka att det på motsvarande sätt finns en "evidensfri zon« i konventionell behandling av barn med CP-skador. Om fokus hamnar på evidensen riskerar man att missa existensen.

När så habiliteringen börjar förespråka intensivträning, gruppbehandling, föräldraengagemang och förändrade roller för de professionella så kanske vinsterna görs just på "existenssidan". Kanske det finns mer som förenar än som skiljer de olika arbetssätten i slutändan? I diskussionen för och emot CE riskerar dock dessa likheter mellan förespråkare och motståndare att skymmas av retoriska positioneringar. 
Tabell I

Studerade forskningsöversikter (A-D) med respektive studie (24 st) samt angiven evidensnivå

\begin{tabular}{|c|c|c|c|c|}
\hline Studie & $\mathbf{N r}$ & Ingår i FÖ & Angiven evidensnivå & Kommentar \\
\hline Bairstow et al. (1993) & ।. & $\mathrm{B}, \mathrm{C}$ & $\begin{array}{l}\text { Ej angiven: FÖ D skattar } \\
\text { studien som III. }\end{array}$ & $\begin{array}{l}\mathrm{Nr} \text { I, I5-17 är samma } \\
\text { studie }\end{array}$ \\
\hline Bochner et al.(1999) & 2. & $\mathrm{D}$ & V & \\
\hline $\begin{array}{l}\text { Calderon-Gonzalez et al. } \\
\text { (1989) }\end{array}$ & 3. & C & Ej angiven & \\
\hline Catanese et al.(1989) & 4. & $A$ & Kvasiexperimentell & \\
\hline Catanese et al.(1995) & 5. & C,D & $\|$ & \\
\hline Clarke (1973) & 6. & $A, D$ & IV & \\
\hline Coleman \& King (1990) & 7. & A & Kvasiexperimentell & \\
\hline Coleman et al.(1995) & 8. & C,D & Kvasiexperimentell & \\
\hline Cottam et al. (1985) & 9. & $A, C$ & I & \\
\hline Cotton (1974) & 10. & $\mathrm{D}$ & $\vee$ & \\
\hline Heal (1972a) & 11. & $\mathrm{D}$ & $\|$ & $\begin{array}{l}\text { Nr 12-14 är samma } \\
\text { studie }\end{array}$ \\
\hline Heal (1972b) & 12. & $D$ & III & \\
\hline Heal (1974) & 13. & C & $\begin{array}{l}\text { Ej angiven: FÖ D skattar } \\
\text { studien som III. }\end{array}$ & \\
\hline Heal (1976) & 14. & A & Kvasiexperimentell & \\
\hline $\begin{array}{l}\text { Hur \& Cochrane } \\
\text { (1995a) }\end{array}$ & 15. & C,D & III & \\
\hline $\begin{array}{l}\text { Hur \& Cochrane } \\
\text { (1995b) }\end{array}$ & 16. & $\mathrm{D}$ & III & \\
\hline Hur (1997) & 17. & $C, D$ & III & \\
\hline Lind (2000) & 18. & $D$ & $\vee$ & \\
\hline Mc Cormack (1974) & 19. & $A$ & Kvasiexperimentell & \\
\hline Reddihough et al. (1998) & 20. & $C, D$ & । & \\
\hline Shields (1989) & 21. & D & IV & \\
\hline Sigafoos et al. (1993) & 22. & $\mathrm{D}$ & IV & \\
\hline Titchener (1983) & 23. & $D$ & IV & \\
\hline Weber \& Rochel (1992) & 24. & B & Ej angiven & \\
\hline
\end{tabular}

\section{Använda forskningsöversikter (FÖ)}

A. French \& Nommensen (1992)

B. Stukat (1995)

C. Vorland Pedersen (2000)

D. Darrah et al. (2004) 


\section{Referenser}

Angel, B. Ö. (2003) „Evidensbaserte programmer - kunnskapsformer og menneskesyn i sosialt arbeid", Nordisk Sosialt Arbeid, årg 23, nr 2, s. 66-72.

Bairstow P, Cochrane R \& Rusk I (1991) „Selection of Children with Cerebral Palsy for Conductive Education and the Characteristics of Children Judged Suitable and Unsuitable", Developmental Medicine and Child Neurology 33, pp. 984992.

Bairstow P, Cochrane R \& Hur J (1993) Evaluation of Conductive Education for Children with Cerebral Palsy. Final Report (Part I). London: HMSO.

Bairstow, P. \& Cochrane, R. (1993) „Is Conductive Education Transplantable?", British Journal of Special Education, Vol 20, No3, pp. 84-88.

Beckung E, Brogren E \& Rösblad B (2002) „Sjukgymnastiska insatser för barn och ungdom". I E. Beckung, E. Brogren \& B. Rösblad (red.) Sjukgymnastik för barn och ungdom. Teori och tillämpning. Lund: Studentlitteratur.

Bergmark, A. \& Lundström, T. (2006) »Mot en evidensbaserad praktik? Om färdriktningen i socialt arbete», Socialvetenskaplig Tidskrift, årg. 13, nr 2, s. 99-113.

Bernehäll Claesson, I. (2004) „Barns upplevelser av habilitering, skola och fritid samt kommentarer från föräldrar." Socialmedicinsk tidskrift $n r 3$ 2004, s. 240-251.

Björk, B. \& Hasselgren, G. (1994) Petö. En pedagogik i renässans? Lund: Lunds universitet, Lärarhögskolan Malmö (Specialpedagogisk påbyggnadsutbildning. Utvecklingsstörning, 60 p).

Bochner, S. \& Center, Y. (1996) "Implementing Conductive Education in Australia: A Question of Programme Transplantation", Education Psychology, Vol 16, issue 2, pp. 101-193.

Bochner S, Center Y, Chapparo C \& Donelly M (1999) »How effective are programs based on conductive education? A report of two studies", Journal of Intellectual \& Developmental Disability, Vol 24, No 3, pp. 227-242.

Bohlin, U. (2001) 'I vairt land finns inte ordet han- dikapp.' Invandrare med barn med funktionshinder berättar. FOU-rapport 2001:2. Malmö: Malmö högskola, Hälsa och samhälle.

Bolin C, Bovide Lindén P \& Persson S (2003) Barns upplevelser av delaktighet $i$ sin habilitering. Habilitering \& hjälpmedel, FoU rapport 2003:1, Region Skåne. Lund: Region Skåne.

Bower E, Mc Lellan DL, Arney J \& Campbell MJ (1996) "A randomised controlled trial of different intensities of physiotherapy and different goal-setting procedures in 44 children with cerebral palsy", Developmental Medicine and Child Neurology 38, pp. 226-237.

Brante, T. (1984) Vetenskapens sociala grunder en studie av konflikter i forskarvärlden. Stockholm: Rabén \& Sjögren.

Bricher, G. \& Darbyshire, P. (2004) "I know my body, I've lived in it all my life': therapy, surgery and remediation experiences of young people with disabilities", Contemporary Nurse 18 (1-2), pp. 18-33.

Brogren, E. (1999) "Sjukgymnastik». I B. Bille \& I. Olow (red.) Barnhabilitering vid rörelsehinder och andra neurologiskt betingade funktionshinder. Stockholm: Liber AB.

Brown H, Pemberton H, Salts K, Zimmerman R \& Zsargo L (1998) "Conductive Education in the UK: present and future challenges", British Journal of Therapy and Rehabilitation, Vol 5, No 6, pp. 330-333.

Brown, H. (1999) "Conductive education and children with cerebral palsy", British Journal of Therapy and Rehabilitation, Vol 6, No 12, pp. 580-583.

Calderón-González R, Tijerina-Cantú E \& Maldonado-Rodríguez C (1989) "Conductive education in integral rehabilitation of patients with cerebral palsy", Boletin Medico Del Hospital Infantil de Mexico, Vol 46, Issue 4, pp. 265-271.

Catanese A, Cotter C \& Connell S (1989) Knox Special Early Intervention project: Evaluation report. Unpublished manuscript, Spastic Society of Victoria, Melbourne.

Catanese A, Coleman G, King J \& Reddihough D

Ulla Bohlin: Konduktiv pedagogik - mellan evidens och existens? 
(1995) "Evaluation of an early childhood programme based on principles of conductive education: the Yooralla project", Journal of Paediatric Child Health 31, pp. 418-422.

Chu, S. K. H. (1989) »The Application of Contemporary Treatment Approaches in Occupational Therapy for Children with Cerebral Palsy", British Journal of Occupational Therapy, 52 (9), pp. 343-348.

Clarke, J. \& Evans, E. (1973) „Rhytmical intention as a method of treatment for the cerebral palsied patient", Australian Journal of Physiotherapy 19, pp. 57-64.

Coleman, J. \& King, J. (1990) A pilot evaluation of conductive education in Victoria. Unpublished manuscript, La Trobe University, Melbourne.

Coleman G J, King, J A \& Reddihough D S (1995) "A pilot evaluation of conductive educationbased intervention for children with cerebral palsy: The Tongala project", Journal of Paediatric Child Health 31, pp. 412-417.

Coles, C. \& Zsargo, L. (1998) "Conductive Education: Towards an Educational Model", British Journal of Special Education, Vol 25, No 2, pp. 70-74.

Cooper, D. (1986) "'A special kind of magic': Changes in family dynamics arising from parent participation in a conductive education program for children with cerebral palsy", Community Health Studies. Vol X, Number 3, pp. 294-300.

Cottam P, Mc Cartney E \& Cullen C (1985) »The effectiveness of conductive education principles with profoundly retarded multiply handicapped children", British Journal of Disorders of Communication 20, pp. 45-60.

Cotton, E. (1974) "Improvement in motor function with the use of conductive education", Developmental Medicine \& Child Neurology 16, pp. 637-643.

Darrah J, Watkins B, Chen L \& Bonin C (2004) "Conductive education intervention for children with cerebral palsy: an AACPDM evidence report", Developmental Medicine \& Child Neurology 46, pp. 187-203.

Egelund, T. (2006) »Multisystemisk terapi: En metode med tvivlsomme effekter", Nordisk
Sosialt Arbeid, Vol 26, nr 3, s. 207-221.

Eliasson, A-C. (2000) »Träningsprogram enligt modellen Move \& Walk. En utvärdering av insatser för 23 barn", Socialmedicinsk Tidskrift nr 4, s. 374-379.

French, L. \& Nommensen, A. (1992) "Conductive Education Evaluated: Future Directions", The Australian Occupational Therapy Journal, Vol 39, issue 4, pp. 14-24.

Forssberg H, Sanner G \& Rösblad B (1998) »Renässans för sjukgymnastik i behandling av CP-skadade», Läkartidningen, Vol 95, nr 15, s. 16601664.

Hári, M. \& Ákos, K. (1988) Conductive Education. London \& New York: Tavistock/ Routledge.

Hári, M. \& Tillemans, T. (1984) "Conductive education". In D. Scrutton (ed.) Management of the motor disorders of children with cerebral palsy. London: Spastics International Medical Publications.

Heal, L. (1972a) Evaluating an Integrated Approach to the Management of Cerebral Palsy. Volume I of $I V$. Eau Claire: University of Wisconsin.

Heal,L. (1972b) Evaluating an Integrated Approach to the Management of Cerebral Palsy: an Analysis of the Evaluation and Follow-up Data from the Institute for Movement Therapy in Budapest, Hungary, Volume IV of IV. Eau Claire: University of Wisconsin.

Heal, L. W. (1974) „Evaluation of an Integrated Approach to the Management of Cerebral Palsy", Except Child 40, pp. 452-3.

Heal, L. (1976) »The comparison of intact groups using the analysis of covariance", Journal of Special Education, 10, 427-436.

Hur, J. \& Cochrane, R. (1995a) „Academic performance of children with cerebral palsy: a comparative study of conductive education and British special education programmes", British Journal of Developmental Disabilities 41, pp. 33-41.

Hur, J. \& Cochrane, R. (1995b) »Maternal stress and conductive education", International Journal of Special Education 10, pp. 54-62.

Hur, J. (1997) "Skills for Independence for Children with Cerebral Palsy: a comparative longi- 
tudinal study", International Journal of Disability, Development and Education, Vol 44, No 3, pp. 263-274.

Hurwitz E, Leonard C, Ayyangar R \& Simson Nelson V (2003) „Complementary and alternative medicine use in families of children with cerebral palsy", Developmental Medicine \& Child Neurology 45, pp. 364-370.

Jansen L, Ketelaar M \& Vermeer A (2003) „Parental experience of participation in physical therapy for children with physical disabilities", Developmental Medicine \& Child Neurology 45, pp. 58-69.

Larsson, B. (2006) »Allegiance - svårigheten att vara objektiv i psykoterapeutisk effektforskning", Psykisk hälsa, Årg. 47:1, s. 18-27.

Liljeroth, I. (2004) Konduktiv pedagogik - ett specialpedagogiskt kunskapssystem inom omrädet rörelsehinder. Lund: Stiftelsen Bräcke Diakoni, Arcus Förlag.

Lind, L. (1996) Petö-metoden. Konduktiv pedagogik. En alternativ pedagogik och behandlingsform för barn med rörelsehinder. Rapport nr 2 . Stockholm: Lärarhögskolan, Institutionen för specialpedagogik.

Lind, L. (2000) »Parents' views of the efficacy of conductive education in Sweden", European Journal of Special Needs Education, Vol 15, No 1, pp. $42-54$.

Lind, L. (2002) "Bitarna faller på plats". Intervjuer med tre habiliteringsteam om stöd till barn med rörelsehinder och deras familjer. Forskningsrapport nr 32, Stockholm: Lärarhögskolan, Teknik, Kommunikation, Handikapp.

Lind, L. (2003) One More Time-Parents' and habilitation teams' conceptions of conductive education and support to children with motor disabilities. Akademisk avhandling, Stockholm: Pedagogiska institutionen, Stockholms universitet.

Littell JH, Popa M \& Forsythe B (2005) Multisystemic Therapy for social, emotional and behavioural problems in youth aged 10-17. Report 05:01, Nordic Campbell Center.

Llewellyn A, Owens M \& Hogan K (1997) „Research Report: Conductive Education: The Case For Further Research", Early Development and Parenting, Vol 6 (2), pp. 89-91.

Lonton, AP. \& Russell, A. (1989) „Conductive Education, Magic or Myth?", Zum Kinderchirurgie, 44, Suppl. 1, pp. 21-23.

Lundgren, P. (1997) "Etableringen av Move \& Walk i Nässjö är intressant och en tankeställare för oss inom habiliteringen", Sjukgymnasten no 1.

Mac Cormack, A. (1974) "Conductive education reassessed». In P. Cottam \& A. Sutton (eds) Conductive education: A system for overcoming motor disorders. London: Croom Helm.

Macdonald, J. (2001) »The Raeden Early Development Group for Preschool Children with Motor Difficulties", British Journal of Occupational Therapy64 (12), pp. 601-608.

Marthinsen, E. (2004) "Evidensbasert' praxis og ideologi», Nordisk Sosialt Arbeid, årg. 24, nr 4, s. 290-302.

Mullback, L. (1997) Anklagelser. En stridsskrift. Stockholm: Hägglunds förlag.

Morgan, A. \& Hogan, K. (2005) "School placement and conductive education: the experiences of education administrators", British Journal of Special Education Vol 32:3, pp. 149-156.

Månsson, S-A. (2003) "Att förstå sociala insatsers värde», Nordisk Sosialt Arbeid, årg. 23, nr 2 , s.73-80.

Möller, A. \& Nyman, E. (2003) Barn, familj och funktionshinder. Utveckling och habilitering. Stockholm: Liber Förlag.

Nordmark E, Hägglund G \& Lagergren J (2001) "Cerebral palsy in southern Sweden. I. Prevalence and clinical features", Acta Paediatrica 90, pp. 1271-1276.

Ogden, T. \& Amlund Hagen, K. ( 2006) "Virker MST? Kommentarer til en systematisk forskningsoversikt og meta-analyse av MST". Nordisk Sosialt Arbeid, Vol 26, nr 3, s. 222-233.

Pawson, R. \& Tilley, N. (2005) Realistic Evaluation. London: Sage.

RBU (2000) Barn och ungdomar med cerebral pares. Stockholm: Riksförbundet för Rörelsehindrade barn och ungdomar.

Reddihough DS, King J, Coleman G \& Catanese $\mathrm{T}$ (1998) „Efficacy of programmes based on Conductive Education for young children with

Ulla Bohlin: Konduktiv pedagogik - mellan evidens och existens? 
cerebral palsy", Development of Medical Child Neurology 40(11), pp. 763-770.

Reynolds Whyte, S. \& Ingstad, B. (1995) »Disability and Culture: An Overwiew». In B. Ingstad \& S. Reynolds Whyte (eds.) Disability and Culture. Los Angeles: University of California press.

Richt, B. \& Tegern, G. (red.) (2005) Sjukdomsvärldar. Om människors erfarenheter av kroppslig ohälsa. Lund: Studentlitteratur.

Robinson RO, Mc Carthy GT \& Little TM (1989) "Conductive education at the Petö Institute, Budapest", British Medical Journal Volume 299:4, pp. 1145-1149.

Sackett, DL. (1986) „Rules of evidence and clinical recommendations on the use of antithrombotic agents", Chest: 1986:89 (2 suppl): 2S-3S.

Sanner, G. (1999) „Habiliteringsteamet”. I B. Bille \& I. Olow (red.) Barnhabilitering vid rörelsehinder och andra neurologiskt betingade funktionshinder. Stockholm: Liber AB.

SBU (2001) Konduktiv pedagogik - ett pedagogiskt program för barn med Cerebral pares. Alertrapport 53, 2001-10-31, version 2. Stockholm: Statens beredning för medicinsk utvärdering.

Schön, D. (2003) The Reflective practitioner: how professionals think in action. Aldershot: Ashgate.

Scrutton, D. (2004) »Introduction«. In D. Scrutton, D. Damiano \& M. Mayston (eds) Management of the Motor Disorders of Children with Cerebral Palsy. $2^{\text {nd }}$ ed. London: Mc Keith Press.

Sheldon, B. \& Macdonald, G. (1999) Research and Practice in Social care: MIND THE GAP. Centre for Evidence-Based Social Services. Exeter University.

Shields, R. (1989) „Practical application of aspects of conductive education", Australian Journal of Physiotherapy 35; pp. 159-165.

Siebes R, Wijnroks L \& Vermeer A (2002) "Qualitative analysis of therapeutic motor intervention programmes for children with cerebral palsy: an update", Developmental Medicine and Child Neurology, 44, pp. 593-603.

Sigafoos J, Elkins J \& Kerr M (1993) „Short-term Conductive education: An Evaluation Study", British Journal of Special Education, Vol 20, No
4, Research Section.

Soydan, H. \& Vinnerljung, B. (2002) „Några problem i utvärdering av sociala interventioner och utfallsstudier", Socialvetenskaplig Tidskrift nr 2-3, s. 160-174.

Stukat, K-G. (1995) "Conductive education evaluated", European Journal of Special Needs Education, Vol 10, no 2, pp. 154-161.

Sutton, A. (1984) „Conductive Education in the Midlands, Summer 1982: progress and problems in the importation of an educational method", Educational Studies, vol 10, no 2, pp. 121-130.

Taylor, M. \& Emery, R. (1995) „Knowledge of conductive education among health service professionals", European Journal of Special Needs Education 10(2), pp. 169-179.

Titchener, J. (1983) "A preliminary evaluation of conductive education", Physiotherapy 69, pp. 313-316.

Trevarthen, C. \& Burford, B. (1995) »The central role of parents: how they can give power to a motor impaired child's acting, experiencing and sharing", European Journal of Special Needs Education, Vol 10, No 2, pp. 138-148.

Ulfhielm K et al. (2001) Du har rätt att välja! Metoder för sjukgymnastisk behandling vid CP. Stockholm. Riksförbundet för Rörelsehindrade barn och Ungdomar, RBU.

Vorland Pedersen, A. (2000) "Conductive education - a critical appraisal", Advances in Physiotherapy 2, pp. 75-82.

Wallin, E. (2000) Hysteriska mammor eller mammor som inte vill missa tåget. Move\&Walk utifrån ett föräldraperspektiv. FOU-rapport 00-04. Stockholm: Stockholms läns landsting, Handikapp \& Habilitering

Webb, SA. (2001) "Some Considerations on the Validity of Evidence-based Practice in Social Work", British Journal of Social Work 31, pp. 57-79.

Weber, KS. \& Rochel, M. (1992) Konduktive Förderung fur cerebral geschädigte Kinder. Forschungsbericht. Bonn: Bundesministerium fur Arbeit und Sozialordnung.

Wright FV, Boschen K \& Jutai J (2005) »Exploring 
the comparative responsiveness of a core set of outcome measures in a school-based conductive education programme", Child: Care Health and Development, 31(3), pp. 291-302.

www.sbu.se/www/index.asp

Åkerström, M. (2004) Föräldraskap och expertis. Motsättningar kring handikappade barn.
Stockholm: Liber AB.

Ödman, P. \& Öberg, B. (2005) »Effectiveness of intensive training for children with cerebral palsy - a comparison between child and youth rehabilitation and conductive education", Journal of Rehabilitation Medicine 37, pp. 263-270.

\section{Summary}

\section{Conductive education - between evidence and existence?}

In the recent ten-year period conductive education (CE) has been introduced to persons with cerebral palsy (CP) as an alternative to physiotherapeutic training methods provided by the established health care system in Sweden. The concept of CE was developed in Hungary after the Second World War by its founder András Petö and the aim is to assist children to attain "orthofunction", i.e. to be able to adapt and cope with motor disorder problems. Intense training is carried out in a specially arranged setting, following a detailed programme led by a "conductor» integrating all forms of therapy. CE approaches motor disorders as problems of learning and thus offers a different perspective on training and treatment as compared to the mainstream rehabilitation organization for children with disabilities. A review of the literature reveals contrasting findings, with evaluation reports often being negative but with parents expressing positive experiences.
The method has caused debate between the proponents and the doubters. Issues at stake are whether CE is an effective treatment for persons with CP or not, but also that the philosophy behind the method differs from and sometimes clashes with that of the rehabilitation system. This article aims at discussing the concept of $\mathrm{CE}$ as a method for treatment and it highlights evidence-based research on two levels. Many of the published studies of CE projects have methodological limitations. If the arguments for or against the method are based on and limited to the criteria of evidence, other important aspects of the "outcome" may be ignored or underestimated. Some dimensions may not be measured but could, nevertheless, be regarded as important. These issues are of a more existential nature. Hence the title: "Conductive education - between evidence and existence?" 